\title{
THE MEASUREMENT OF AMMONIA IN WHOLE BLOOD
}

\author{
BY \\ V. M. ROSENOER \\ From the Metabolic Unit, St. George's Hospital, London
}

(RECEIVED FOR PUBLICATION OCTOBER 14, 1958)

The recent widespread interest in blood ammonia determinations in normal and abnormal clinical states (McDermott and Adams, 1954; Schwartz, Phillips, Gabuzda, and Davidson, 1953 ; White, Phear, Summerskill, and Sherlock, 1955), together with discrepant reports from various laboratories, have prompted a critical examination of the Conway microdiffusion technique in blood analysis.

\section{Method}

The method adopted was essentially that described by Conway (1950) with the following modifications. No. 2 units were used with $\mathrm{N} / 4000 \mathrm{Ba}(\mathrm{OH})_{2}$ in the burette, $0.1 \mathrm{ml}$. N/2000 $\mathrm{HCl}$ in the centre compartment of the unit, and $0.2 \mathrm{ml}$. saturated $\mathrm{K}_{2} \mathrm{CO}_{3}$ and $0.2 \mathrm{ml}$. standard solution or blood in the outer compartment. The measuring error was estimated at $5 \%$. In order to avoid difficulties with the end-point, the blood/carbonate mixture was removed by water pump aspiration immediately before titrating the residual acid.

In this series of analyses blood was withdrawn from the patient with a $5 \mathrm{ml}$. syringe and No. 1 needle without venous stasis, collected into a bottle containing 50 units of dried heparin, rapidly mixed, and samples withdrawn for analysis two minutes after the beginning of the venipuncture. With practice this could be timed very accurately.

No significant difference was found between heparinized blood and fresh unclotted samples. In some experiments ammonium sulphate was added to the blood using the stock ammonium sulphate solution $\left(100 \mu \mathrm{g}\right.$. $\mathrm{NH}_{3}-\mathrm{N}$ per ml.) in microlitre quantities, thereby producing negligible dilution of the blood samples.

\section{Results}

Serial estimations of the ammonia in standard ammonium sulphate solutions, in samples of freshly shed heparinized normal blood, and in heparinized normal blood, to which measured quantities of ammonium sulphate had been added, were made after given intervals of incubation at room temperature $\left(23^{\circ} \mathrm{C}\right.$. $)$.

These results are shown in Figs. 1-4. It is interesting to note that, when the difference between the curves for normal blood and that for blood plus added ammonia is plotted, a very accurate estimate of the added ammonia can be obtained.

Estimations of the ammonia content of blood from cirrhotic patients were made in the same manner. Two typical curves are shown (Fig. 5).

\section{Discussion}

The following interpretation for the results is suggested. The ammonia determined in blood under these experimental conditions is made up of two parts: (1) Pre-formed ammonia in the blood sample; (2) ammonia produced during the experiment by the deaminating action of the potassium carbonate.

That pre-formed ammonia can be accurately estimated in blood is demonstrated in those experiments in which ammonium sulphate has been added to normal blood. The plotted recovery curves compare favourably with the curves of ammonia from the standard solutions. However, the amount of ammonia found in blood continues to rise as the incubation period is prolonged. This rise is almost certainly due to the slow production of ammonia by alkaline deamination and not to delayed liberation of pre-formed ammonia.

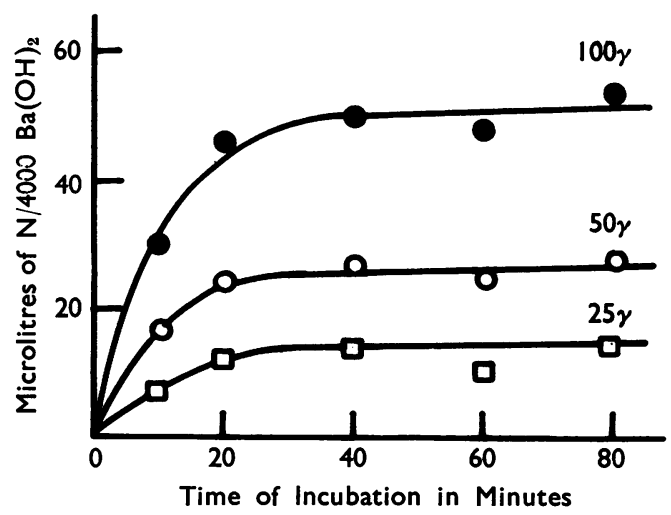

FIG. 1.-Recovery of ammonia from standard ammonium sulphate solutions containing 100,50 , and $25 \mu \mathrm{g}$. $\mathrm{NH}_{3}-\mathrm{N}$ per $100 \mathrm{ml}$. The ordinate represents the amount of $\mathrm{HCl}$ (expressed in terms of $\mathrm{Ba}(\mathrm{OH})_{2}$ ) neutralized by the liberated ammonia. 


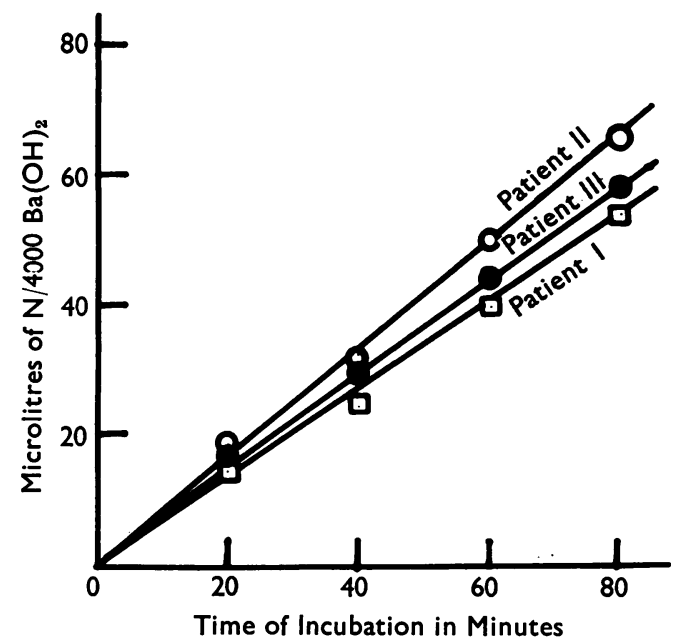

FIG. 2.-Recovery of ammonia from heparinized blood (shed two minutes) incubated at room temperature $\left(23^{\circ} \mathrm{C}\right.$.) for varying periods.

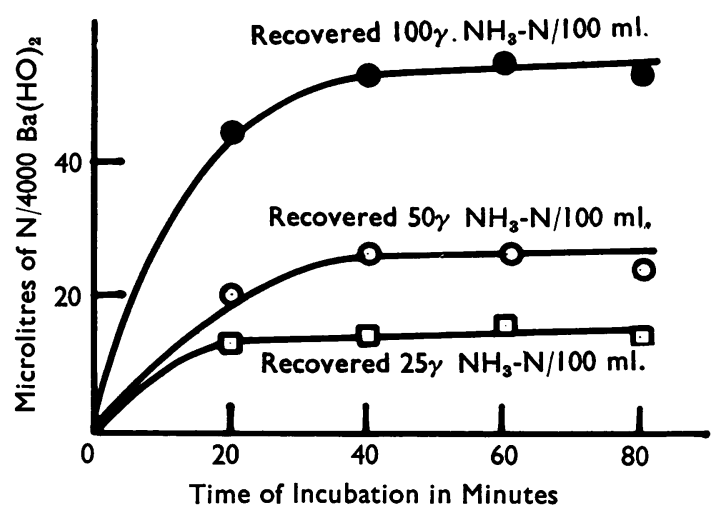

FIG. 4.-Recovery of ammonia added to heparinized blood. These curves represent the difference between the recoveries shown in Figs. 2 and 3.

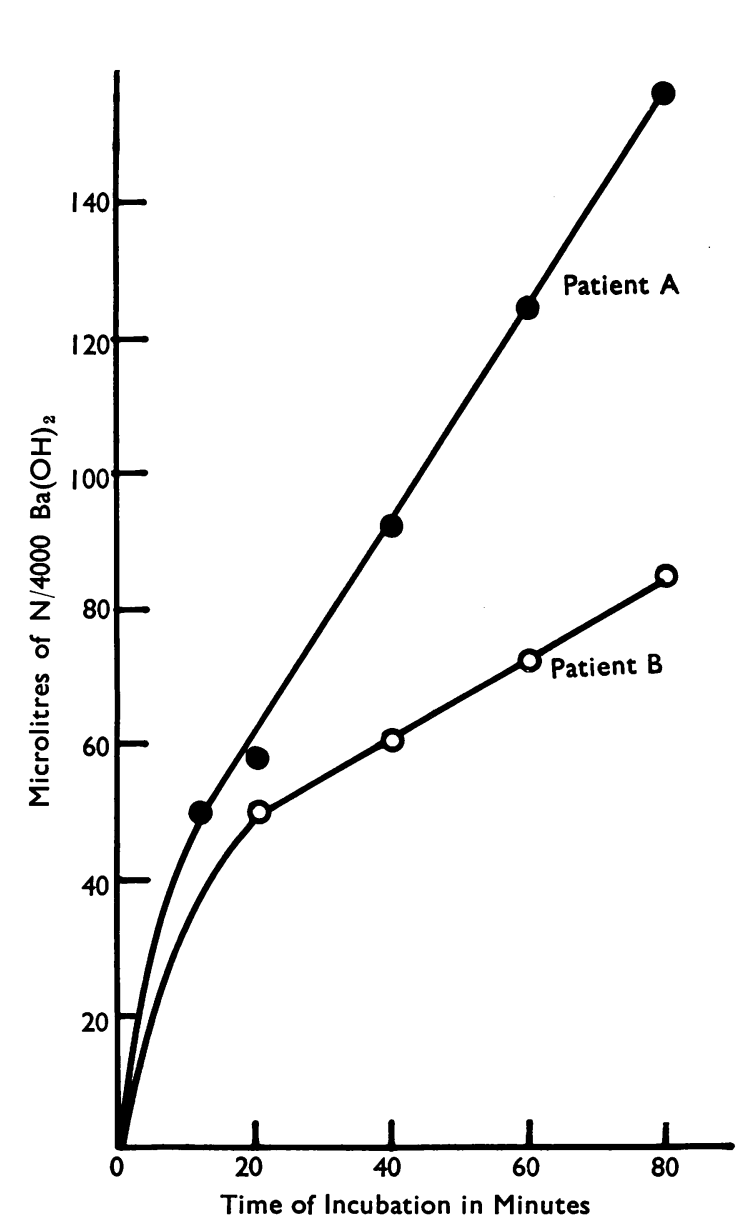

Fig. 5.-Recovery of ammonia from heparinized blood from cirrhotic patients. 


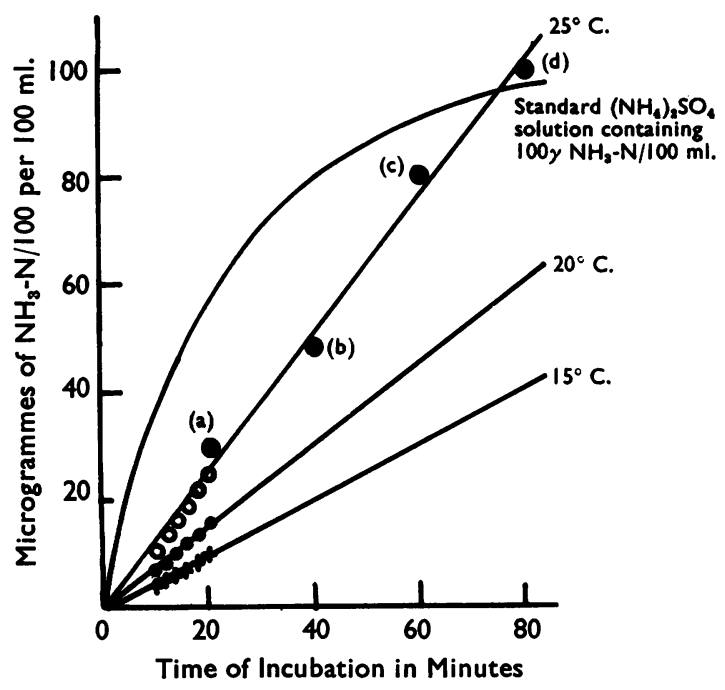

Fig. 6.-Replot of Conway's recovery curve for ammonia from a standard solution together with plots of the correction factors for normal blood at various temperatures (extrapolated). The additional points $a, b, c, d$, represent the recowery of ammonia from the blood of Patient 1 incubated at $23^{\circ} \mathrm{C}$. for varying periods.

Conway made a negative correction for the "special deaminating action of the alkali." $\mathrm{He}$ stated that the ammonia formed by the alkali is strictly linear with time over a few hours (Conway, 1935). From his published figures the ammonia liberated by the alkaline deamination of blood had been correlated with the ammonia found in a standard ammonium sulphate solution (Fig. 6). There is a striking similarity with our figures for normal freshly shed blood analysed at room temperature $\left(23^{\circ} \mathrm{C}\right.$. $)$. This artefact appears to be immeasurably larger than the pre-formed ammonia in normal freshly shed blood and cannot be disregarded. Should, however, it be constant, a simple correction factor could be applied. Variations were noted with the samples of normal blood evaluated, but these could have been attributed to experimental error ; in the case of abnormal blood, however, this interpretation cannot be sustained. Furthermore, there is no $a$ priori indication that the alkali deaminable constituents of abnormal blood will be present in the same concentration as in normal blood.

It is possible to apply individual correction factors to each sample by making the following assumptions :

(a) All the pre-formed ammonia in the sample will have been recovered in 40 minutes (within the limits of experimental error).

(b) All the ammonia recovered in the subsequent 40 minutes is attributable to deamination.

(c) There is no change in the rates of deamination or recovery of ammonia throughout the experiment.

We have no reason to doubt that these assumptions are correct, but further work will be required to verify this modification.

\section{Conclusions}

In this brief study of the Conway microdiffusion technique as applied to blood, we have concentrated merely on the artefact produced by alkaline deamination occurring during the period of incubation. We conclude that this artefact forms a disproportionate part of the estimated ammonia, and that whilst Conway's correction factors are confirmed for normal blood these factors cannot be applied indiscriminately to abnormal blood. The amount of pre-formed ammonia in blood is much more accurately measured as the difference between the ammonia liberated in the first 40 minutes and that liberated in the second 40 minutes of incubation; in normal fresh blood it is extremely small.

\section{REFERENCES}

Conway, E. J. (1935). Biochem. J., 29, 2755. (1950). Microdiffusion Analysis and Volumetric Error, 3rd ed. Crosby Lockwood, London.

McDermott, W. V., and Adams, R. D. (1954). J. clin. Invest., 33, 1 Schwartz, R., Phillips, G. B., Gabuzda, G. J., and Davidson, C. S. (1953). J. Lab. clin. Med., 42, 499.

White, L. P., Phear, E. A., Summerskill, W. H. J., and Sherlock, S. (1955). J. clin. Invest., 34, 158. 